\title{
Usage and Risk of Hydrocarbon Refrigerants in Motor Cars for Australia and the United States
}

\author{
I. L. Maclaine-cross \\ School of Mechanical and Manufacturing Engineering, The University of New \\ South Wales, UNSW Sydney 2052, Australia
}

\begin{abstract}
Commercial replacement of fluorocarbons in mobile air conditioning systems (MACS) with typically HC-290/600a[60/40] and minimal precautions began in Idaho in 1993. R290/600a has low environmental impact but mixed with air is flammable and frequencies for fire, injury and cabin overpressure were predicted. No such accidents are known from 1993 to mid-2003.

R290/600a suppliers consumption, representative MACS charges and charge termination frequency were used to predict yearly total MACS numbers. Mid-2002 in Australia there were $0.33 \times 10^{6}$ and at end 2002 in the USA $4.7 \times 10^{6} \mathrm{R} 290 / 600 \mathrm{a}$ MACS. Integrating over time gave usage for Australia to the end 2002 as $1.09 \times 10^{6}$ car-years and to mid-2003 for the USA $21.7 \times 10^{6}$ car-years.

The measured US fire, injury and cabin overpressure frequencies are less than $3.2 \times 10^{-7}$ per car year with high probability. This fire frequency is a hundred times lower than predicted because most R290/600a leaks in MACS use are effectively nonflammable.
\end{abstract}

Key words: hydrocarbon refrigerant; car; automobile; air conditioning.

\section{Introduction}

P. J. van der Weyde of Philadelphia invented hydrocarbon refrigerants in 1866 [1]. Ethane R170, propane R290 and isobutane R600a were successfully marketed by the Linde companies in the 1920s and 1930s. Since 1967 hydrocarbon refrigerants have liquefied natural gas in plants which are now larger than $100 \mathrm{MW}$ of cooling. Hydrocarbon refrigerants for domestic appliances were revived in Germany in 1992 and R600a refrigerators have spread worldwide. Large scale replacement of fluorocarbon by hydrocarbon refrigerant in 
mobile air conditioning systems (MACS) commenced in Idaho in 1993. Motivations for this were no ozone depletion, lower global warming, lower cost and better performance [2]. A typical composition for 'drop-in' replacement of 1,1,1,2-tetrafluoroethane (R134a) in MACS is R290/600a [60/40] but R600a is believed optimum for new MACS designs [3].

Hydrocarbon refrigerants mixed at 2 to $10 \%$ by volume in air are flammable. When retrofitting R134a with R290/600a in MACS in Australia and the USA the following simple precautions are usually taken [4]. Suppliers odorize the refrigerant. Mercury-in-glass thermometers are not used for testing the MACS. Motor cars without fresh and exhaust cabin vents are not retrofitted to R290/600a. In the passenger cabin, damaged mountings or screw fittings are replaced and metal extensions substituted for elastomer hoses. The initial charge is carefully weighed and is less than both $400 \mathrm{~g}$ and a third the R134a charge by mass. The R290/600a charge was typically $300 \mathrm{~g}$ when replacing R12 in the early 1990s but is now typically $200 \mathrm{~g}$ in new MACS. Secondary cabin loops, dump and flow limiting valves additional to the expansion valve are not used.

Accident risk is the product of consequences and frequency [5]. For hydrocarbon refrigerants in car air conditioners this paper gives measured or actual flammability accident frequencies, compares with literature predictions and explains the discrepancy. Section 2 describes how numbers and usage of hydrocarbon MACS were estimated from suppliers' data for both Australia (Section 3) and the United States of America (Section 4). Predicted and measured frequencies of additional fires, injuries and overpressure are summarized (Section 5) and the predicted fire frequencies are shown to be hundreds of times the measured frequency (Section 6). The high predictions result from ignoring the nonflammability of most hydrocarbon MACS leaks (Section 7).

\section{Estimation of System Numbers and Usage}

The charge is the mass of all refrigerant consumed in charging one empty MACS or recharging once in service. The charge for an empty MACS may be marked on the car or in the owner's manual. Some R290/600a suppliers publish charge tables for cars [6]. During charging, refrigerant is released to the atmosphere in purging the charging lines of air, purging air from the MACS and from the charging lines when they are uncoupled. The remaining mass leaks to the atmosphere over the charge life. After about half the charge has leaked the MACS cooling capacity will start to drop noticeably and the owner will eventually consider a recharge. Consequently a representative average refrigerant mass inside a MACS in use is about $2 / 3$ of the nominal charge [7]. 
For recharging MACS, disposal of previous charge remains is by: recovery under vacuum then recycling; release to atmosphere (regas); or leaving inside the system (top-up) [2]. Regas is the usual procedure for R290/600a in Australia. In the USA, regas is illegal and large garages purchase R290/600a in $20 \mathrm{~L}$ or larger cylinders and send recovered R290/600a for processing elsewhere or burn it outdoors. About half the US R290/600a is sold in $0.3 \mathrm{~L}$ cans to motorists and small garages who use the top-up procedure. Top-up uses about $2 / 3$ the new refrigerant mass used for regas or recovery.

The charge life is the time between charging or charging and scrapping. Charge life will vary from MACS to MACS and from charge to charge. For UK MACS, a typical average charge life used was 5.5 years [7]. For Asian MACS, Aisbett and Pham [8] assume 40\% emission factor implying a charge life of $1 /(0.4 \times$ $2 / 3)=3.75$ years. For Australian R134a MACS, a 29.2\% emission factor was used which implies a charge life of 5.14 years [9]. Here, the average charge life used is $L=5$ years.

The frequency density of charge termination, $f$, is the probability density of failure or replacement of a particular charge at any time in its life. The life curve is the frequency density, $f$, as a function of time, $t$. Many car owners recharge their MACS every year but most wait until cooling capacity has decreased. The leakage on a few MACS is so low that the charge lasts twice the average life $L$. Assuming all MACS charges have the same life or $f=\delta(L)$ is inconsistent with these possibilities [8]. A constant charge failure probability implies the life curve is given by $f=\frac{1}{L} \mathrm{e}^{-t / L}$, a negative exponential [10]. This relationship gives too many very short and very long lived charges compared with that observed. A constant termination frequency $f=1 /(2 L)$ for $0<t<$ $2 L$ is more consistent with most existing knowledge about charge life.

The average charge, $c$, is the average mass of a particular refrigerant consumed in charging a MACS in a particular country. The average charge depends on charging method and MACS design and so varies with time. The consumption rate, $C$, is the product of the average charge, $c$, and the frequency of charging with the refrigerant for all MACS in the country. The frequency of charging depends on legislation, vehicle population, charge life and commercial factors. Charge count, $N$, is the total number of MACS charged with the refrigerant in a country. The effect of releases to atmosphere on these variables is indirect, some like purging effect the average charge and some like leakage effect the charge life. The calculation of atmospheric releases [7-9] should not be confused with the calculation here of the number of MACS charged with a refrigerant. The two problems have common data but principles and equations differ.

From consumption rate of replacement refrigerant, $C$, and average MACS replacement charge, $c$, the creation rate of replacement MACS charges in a 
country is $\frac{C}{c}$. For MACS replacement charges created at time, $T$, during time interval, $\mathrm{d} T$, the termination rate at time, $t$, is $\frac{C}{c} f(t-T) \mathrm{d} T$. The total termination rate in a country at time, $t$, is the integral of this over all times $T$ previous to $t$ which is $\int_{-\infty}^{T=t} \frac{C}{c} f(t-T) \mathrm{d} T$. The rate of increase in charge count is $\mathrm{d} N / \mathrm{d} t$ and is related to the previous two rates by Equation 1:

$$
\text { rate of increase }=\text { creation rate }- \text { termination rate }
$$

Substituting the previous expressions for these rates into Equation 1 gives Equation 2:

$$
\frac{\mathrm{d} N}{\mathrm{~d} t}=\frac{C}{c}-\int_{-\infty}^{T=t} \frac{C}{c} f(t-T) \mathrm{d} T
$$

and for constant termination frequency $f=1 /(2 L)$ the integral in Equation 2 simplifies giving Equation 3:

$$
\frac{\mathrm{d} N}{\mathrm{~d} t}=\frac{C}{c}-\frac{1}{2 L} \int_{t-2 L}^{T=t} \frac{C}{c} \mathrm{~d} T
$$

The time dependence of data for $C$ and $c$ allows only numerical solution of Equation 3. For a difference, $\Delta t$, the derivative may be evaluated using a central difference and the integral using the midpoint rule. If for period $i$, average refrigerant consumption rate is $C_{i}$ and average refrigerant charge is $c_{i}$, the number $N_{i}$ of MACS charged at the end of the period is calculated using:

$$
N_{i}=N_{i-1}+\Delta t \frac{C_{i}}{c_{i}}-\frac{(\Delta t)^{2}}{2 L} \sum_{i-2 L / \Delta t}^{j=i} \frac{C_{j}}{c_{j}}
$$

where before the refrigerant is first used $i \leq 0$ and $C_{i}=N_{i}=0$. After use commences, $i>0$ and Equation 4 is applied successively to calculate all $N_{i}$. If $\Delta t$ is chosen as one year with the peak annual consumption in its middle Equation 4 is most accurate. Equation 4 implies that a MACS is not necessarily recharged with the replacement refrigerant but is added to the pool of MACS which might be charged with this refrigerant.

Usage in car-years $U$ is the integral $\int N \mathrm{~d} t$ of cars $N$ with respect to time $t$. Since $N$ is known only at the end of the consumption period an approximate method of integration must be used. The most accurate method for functions 
Table 1

Refrigerant consumption $C_{i}$ by Australian MACS; average MACS charge $c_{i}$; number of motor cars charged with R290/600a at end of financial year $N_{i}$; and usage in caryears at year end $U_{i+\frac{1}{2}}$.

\begin{tabular}{|l|ccccccc|}
\hline Financial Year & $95 / 96$ & $96 / 97$ & $97 / 98$ & $98 / 99$ & $99 / 00$ & $00 / 01$ & $01 / 02$ \\
\hline$C_{i} \mathrm{Mg} / \mathrm{yr}$ & 2.85 & 10.12 & 15.86 & 21.30 & 24.30 & 23.82 & 25.33 \\
$c_{i} \mathrm{~g}$ & 300 & 290 & 280 & 270 & 260 & 250 & 240 \\
$N_{i} 10^{3} \times$ & 8.6 & 39.0 & 85.5 & 146.4 & 212.6 & 271.0 & 329.1 \\
$U_{i+\frac{1}{2}} \mathrm{yr} 10^{3} \times$ & 8.6 & 47.6 & 133.1 & 279.6 & 492.1 & 763.1 & 1092.2 \\
\hline
\end{tabular}

of this type is the mid-point rule. So:

$$
U_{i+\frac{1}{2}}=U_{i-\frac{1}{2}}+\Delta t N_{i}
$$

where $U_{\frac{1}{2}}=0$ and Equation 5 is applied successively for $i>0$ to calculate all $U_{i+\frac{1}{2}}{ }^{2}$.Equation 5 gives usage six months after the times $t_{i}$ for which $N_{i}$ is known.

\section{Australian Use}

Table 1 gives consumption calculated from data supplied by Australian suppliers and the average R290/600a charge for Australian MACS. In the early 1990s there was a step change in the average charge of new MACS from about $300 \mathrm{~g}$ to $200 \mathrm{~g}$ [6]. The annual decline in the average MACS charge results from the gradual market penetration of these new MACS.

Consumption occurs mostly in summer so the financial or taxation year from 1st July to 30th June of the following year was used to minimize fluctuations from allocating shipments to the wrong period.

In the Australian states of New South Wales and Queensland, use of R290/600a for MACS has been severely restricted by legislation introduced late in 1995 for all the years in Table 1 . There is no restrictive legislation nationally or in the other six states and territories [2].

The uncertainty in the Table 1 data was estimated to be $\pm 10 \%$ for consumption, $\pm 10 \%$ in average charge and $\pm 30 \%$ in average charge life. If a fixed charge life of 5 years was used, the number of MACS calculated for mid-2002 would have been $31 \%$ higher than Table 1. This was taken as an estimate of the uncertainty in MACS numbers due to differences between the real and assumed life curves. Equations 4 and error theory show that the uncertainty in the num- 
Table 2

Refrigerant consumption $C_{i}$ by United States MACS; average MACS charge $c_{i}$; number of motor cars charged with R290/600a at end of year $N_{i}$; and usage in car-years at mid-year $U_{i-\frac{1}{2}}$.

\begin{tabular}{|l|ccccccccccc|}
\hline Year & 1993 & 1994 & 1995 & 1996 & 1997 & 1998 & 1999 & 2000 & 2001 & 2002 & 2003 \\
\hline$C_{i} \mathrm{Mg} / \mathrm{yr}$ & 61.2 & 82.3 & 70.5 & 133.7 & 164.1 & 144.2 & 237.5 & 334.7 & 201.6 & 247.1 & \\
$c_{i} \mathrm{~g}$ & 250 & 250 & 250 & 225 & 220 & 215 & 210 & 205 & 200 & 195 & \\
$N_{i} 10^{3} \times$ & 220 & 492 & 689 & 1138 & 1664 & 2048 & 2779 & 3849 & 4193 & 4670 & \\
$U_{i-\frac{1}{2}} \mathrm{yr} 10^{3} \times$ & & 220 & 713 & 1402 & 2539 & 4204 & 6252 & 9031 & 12880 & 17073 & 21742 \\
\hline
\end{tabular}

ber of R290/600a MACS at 30th June 2002 is $\pm 36 \%$ and with Equations 5 show the uncertainty in the usage at 31st December 2003 is $\pm 33 \%$.

\section{United States Use}

Table 2 is based on the calendar year which starts and ends in the northern winter. The consumption data comes from US suppliers of R290/600a for MACS.

The average R290/600a charge for 1992 US MACS was approximately one US pint or $250 \mathrm{~g}$ R290/600a [11]. The average early 1990s charge for top-up with US MACS was $200 \mathrm{~g}$ and for regas or recovery $300 \mathrm{~g}$. US R290/600a sales are half in $0.3 \mathrm{~L}$ cans used for top-up and half in cylinders used for regas or recovery.

In the early 1990s, the factory charge of new US MACS changed from R12 to R134a usually with a reduction in the mass. This gave a step change in the average R290/600a regas charge of new MACS from about $300 \mathrm{~g}$ to $200 \mathrm{~g}$ as in Australia [6]. The 1996 10\% drop in average R290/600a MACS charge $c_{i}$ of Table 2 occurred because under the US Clean Air Act R290/600a could not directly replace R12 after 13th July 1995. The annual decline after 1996 results from the gradual market penetration of new R134a MACS. In 2002, R134a MACS were about $74 \%$ of US MACS presenting for service [12].

In about 20 US states there are laws applicable to flammable or toxic refrigerants. These either apply equally to R134a and R290/600a or require compliance with the US Clean Air Act within the state. They do not add to the restrictions of the Clean Air Act [2].

The uncertainty in the Table 2 data was estimated to be $\pm 10 \%$ for consumption, $\pm 20 \%$ in average charge and $\pm 30 \%$ in average charge life. If a fixed 
charge life of 5 years was used, the number of MACS calculated for end 2002 would have been $22 \%$ higher than Table 2 . This was taken as an estimate of the uncertainty in MACS numbers due to differences between the real and assumed life curves. Equations 4 and error theory show that the uncertainty in the number of R290/600a MACS at 31st December 2002 is $\pm 37 \%$ and with Equations 5 show the uncertainty in the usage at 30th June 2003 is $\pm 36 \%$.

The Mobile Air Conditioning Society Worldwide [12] included hydrocarbon refrigerant in its 2002 survey of refrigerant usage at 109 US independent service facilities. Of the vehicles presented for repair only $6.4 \times 0.31=1.98 \%$ appeared to be charged with hydrocarbon refrigerant. For $215 \times 10^{6}$ US MACS [12] this equates to $0.0198 \times 215 \times 10^{6}=4.27 \times 10^{6}$ R290/600a MACS in the USA. Table 2 gives $4.19 \times 10^{6}$ US R290/600a MACS possibly needing service in summer 2002 which is well within the $\pm 36 \%$ uncertainty of $N_{i}$ in Table 2 .

\section{Predicted and Measured Frequencies of Accidents}

Table 3 gives predictions by various authors of the frequencies for additional fires, injuries and cabin overpressures from using R290/600a in a MACS. The table indicates the country of the data used in frequency predictions and whether the prediction was an upper limit. A leak of R290/600a might catch fire, the flame might burn a person (injury) and the resulting cabin overpressure might remove windows. The predicted frequencies for these accidents are relative to a completely nonflammable refrigerant like R744 (carbon dioxide) or R12. They are predictions of future accident statistics. A ' - ' indicates the authors did not consider such scenarios. A '0' upper limit indicates the authors considered such scenarios impossible. The frequency of car fires from all non-malicious causes is about $10^{-3}$ per car year [5].

Lindgren [11] predicted risk of hydrocarbons in MACS as “... as safe as, natural gas or propane heat,...". The two frequencies by [11] in Table 3 are from US 1998 domestic heating, fire, injury and death totals divided by four times US population which allows for different usage of cars and furnaces.

After complaints in 1993, the Office of Defects Investigation in the US National Highway Traffic Safety Administration (NHTSA) twice investigated OZ-12 an R290/600a product of OZ Technology Inc., Idaho. No instances of OZ-12 leaking from a MACS in use then catching fire were found. The conclusion of the investigations was 'no safety defect trend' [16].

The NHTSA database http://www.nhtsa.gov/ records the 1993 and 1994 investigations. In 2003, there are still no NHTSA records of hydrocarbon refrigerant leaking from a MACS in service and igniting. No one I have asked in 
Table 3

Predicted and measured frequencies per car-year of additional fires, injuries and overpressures from using hydrocarbon refrigerants in MACS.

\begin{tabular}{|c|c|c|c|c|c|}
\hline \multirow{2}{*}{ Reference } & country & upper & fire & injury & overpressure \\
\cline { 3 - 6 } & & limit? & \multicolumn{2}{|c|}{ Predicted frequencies per car-year } \\
\hline$[13]$ & US & no & $0.52 \times 10^{-4}$ & $0.35 \times 10^{-6}$ & - \\
{$[11]$} & US & yes & $0.45 \times 10^{-4}$ & $1.7 \times 10^{-6}$ & 0 \\
{$[5]$} & UK & no & $0.93 \times 10^{-4}$ & $0.305 \times 10^{-6}$ & $4.16 \times 10^{-10}$ \\
{$[14]$} & AU & yes & $1.0 \times 10^{-4}$ & $1.0 \times 10^{-6}$ & $8 \times 10^{-10}$ \\
{$[15]$} & AU & yes & - & $0.25 \times 10^{-6}$ & 0 \\
\hline & & & Measured frequencies per car-year \\
\hline Sec. 3 \& 5 & AU & no & 0 & 0 & 0 \\
Sec. 4 \& 5 & US & no & 0 & 0 & 0 \\
\hline
\end{tabular}

Australian or USA, government, insurance, research or car or refrigerant manufacture knows of any such fire. Rapid R290/600a charge leaks after collisions which did not ignite have occurred [15]. In 1996, a MACS in New Zealand charged with R134a leaked rapidly after a collision and the ester oil ignited showing that MACS fires are possible [17]. No recorded accidents of any of the three types in either Australia or the USA makes the most likely value of the measured frequencies in Table 3 zero.

\section{Statistical Comparison of Accident Frequencies}

The usages, $U$, in Tables 1 and 2 allow statistical comparison of the frequency predictions in Table 3 with measured data.

If the fire frequency was $0.45 \times 10^{-4}$ per car-year (lowest predicted in Table 3 ), the expected number of fires during the $1.09 \times 10^{6}$ car-years to end 2002 in Australia (Table 1) is 49. If this frequency is correct for the Table 1 usage, the Poisson distribution [18] gives the probability of no fires reported as $4 \times 10^{-22}$ which is statistically very significant. One fire might occur with no or an erroneous report recorded but if 10 fires had occurred one would be certain that at least one would be reported. The predicted probability of 0 to 10 fires occurring is $1.4 \times 10^{-11}$ still very significant. There are only 1.4 chances in $10^{11}$ of the lowest predicted fire frequency in Table 3 being too low for the actual Australian data. For the US data the chances that the actual frequency is as high as the lowest predicted in Table 3 are very much lower. 
The reported fire frequency which has less than 1 in a 1000 chance of being too high given zero US reports is $3.2 \times 10^{-7}$ per car year. This is more than a hundred times lower that the lowest fire frequency predicted in Table 3 . The reported injury and overpressure frequency also have less than 1 in a 1000 chance of exceeding $3.2 \times 10^{-7}$ per car-year.

The lowest predicted frequency of reported injuries in Table 3 is $0.25 \times 10^{-6}$ and for the $2.17 \times 10^{7}$ car-years to mid-2003 in the US one would expect 5.4 injuries. The Poisson distribution gives the probability of no injuries as 0.0044. In other words, there are only 4.4 chances in a thousand of the lowest predicted injury frequency in Table 3 being too low.

Cabin overpressure accidents have extremely low predicted frequency (Table 3). Many decades of data with high market penetration might find which predicted frequency is most likely. The direct consequences to occupants are minor burns to exposed skin and the predicted risk is less than $8 \times 10^{-5} A \$ /$ caryear [14] making low relative error in frequency unimportant.

\section{Ignition Probability}

Lunde and Lorentzen [19] found that a toxic refrigerant flammable in air but with an odour can have lower accident frequency and risk than a nontoxic, nonflammable, odorless refrigerant. The presence of odour from a leak warns people to take appropriate precautions. Almost all R290/600a used in MACS is odorized and this may be partly responsible for there being no recorded injuries or overpressures (Table 3).

Most of the predicted fires in Table 3 were condenser leaks igniting following collisions. For example, [14] gave the frequency of leaks following collisions of 0.01 per car-year and multiplied this by a 0.01 conditional probability of ignition. Odour has no effect for most fire scenarios as occupants are in the cabin and the leak is in the engine bay.

A typical MACS leak is less than $1 \mathrm{mg} \mathrm{s}^{-1}$ which is too small to sustain a flame since the heat loss at flame temperature is greater than the heat generation rate $[20]$.

Leaks up to $15 \mathrm{~g} \mathrm{~s}^{-1}$ peak have been measured from MACS [4] and are possible after collisions. While liquid R290/600a remains above $-20^{\circ} \mathrm{C}$, the pressure in the MACS will be over $189 \mathrm{kPa}$. The jet from most such leaks only slows below the flame velocity when it has mixed with air below the flammable limit. It is flammable only with a permanent ignition source [21]. Cars in normal operation have no exposed ignition sources for R290/600a [14] and 
permanent ignition sources are created in few collisions.

Fracture of the MACS liquid receiver or attached tubes in a collision can produce a leak rate up to $300 \mathrm{~g} \mathrm{~s}^{-1}$ [21] for less than $1 \mathrm{~s}$. About $200 \mathrm{~g}$ of R290/600a liquid can flash to a $25 \mathrm{~L}$ white cloud. The cloud is initially about 7 times denser than air but is flammable only at its boundary. Normal atmospheric motion removes it from possible ignition sources in less than $2 \mathrm{~s}$ and dilutes it below flammable in less than $10 \mathrm{~s}$. Only cases without ignition are known [15].

For the previous reasons, R290/600a is nonflammable under the conditions of most leaks. This is consistent with the actual conditional probability of ignition being hundreds of times smaller than assumed for the fire frequency predictions in Table 3.

\section{Conclusion}

The number of mobile air conditioning systems using HC-290/600a in Australia was $0.33 \pm 0.12 \times 10^{6}$ mid-2002 and in the United States of America was $4.7 \pm 1.7 \times 10^{6}$ at end 2002. The usage for Australia was $1.09 \pm 0.36 \times 10^{6}$ car-years at end 2002 and for the USA $21.7 \pm 7.8 \times 10^{6}$ car-years mid-2003. Tables 1 and 2 give R290/600a MACS numbers and usage at dates from 1993 to 2003.

The predicted extra recorded frequencies of fire, injury and cabin overpressure in Table 3 from using R290/600a MACS are low and agree but no such accidents are known. The US usage shows that statistically there is only 1 chance in 1000 that the true recorded accident frequencies are greater than $3.2 \times 10^{-7}$ per car year. For fires this is consistent with the ignition probability being hundreds of times less than used in predictions and most R290/600a leaks being effectively nonflammable.

The actual accident frequency and hence risk of using hydrocarbon refrigerant in motor cars is much lower than predicted when commercial use commenced.

\section{Acknowledgements}

The author is grateful to J. Batterton, J. K. Clark, G. Lindgren, R. Small, C. Spencer and P. Williams for charge and confidential consumption data. 


\section{References}

[1] Thévenot R, translator Fidler JC. A History of Refrigeration throughout the world. Paris: International Institute of Refrigeration, 1979. 476 p.

[2] Maclaine-cross IL, Goedhart J. Hydrocarbon Refrigerants in Australian Cars. In: GTZ Proklima Yearbook 1997-1999, Developments and Trends in ODS Phase Out. Eschborn Germany, 1999. p. 105-20.

[3] Maclaine-cross IL, Leonardi E. Why hydrocarbons save energy, AIRAH Journal $1997 ; 51,6 ; 33-38$.

[4] Maclaine-cross IL. Refrigerant Concentrations in Car Passenger Compartments. Conference Proceedings, International Conference on Ozone Protection Technologies, November 12-13th, Baltimore MD, 1997, p. 403-12.

[5] Arthur D Little Ltd. Risk Assessment of Flammable Refrigerants, Part 3: Car Air Conditioning. Final Report to Calor Gas Ltd, Cambridge, UK, 1995, 25 p.

[6] HR12 Motor Vehicle Weight Chart. HyChill Refrigerants, Kilsyth VIC, Australia, 2000, 16 p.

[7] Johnson E, Banks E, Sharratt P. Global Warming Comparison of Hydrocarbons and HFC-134a in Automobile Air Conditioning. Atlantic Consulting, London, 1996, 9 p.

[8] Aisbett EK, Pham QT. Natural replacements for ozone-depleting refrigerants in eastern and southern Asia. Int J Refrigeration 1998;21;18-28.

[9] Jubb C, Bennett M, Fraser P. Inventories and Projections of Ozone Depleting and Synthetic Greenhouse Gases used in Montreal Protocol Industries. Environment Australia, Canberra, Section 6.3.1, 2002, 135 p.

[10] Houlden BT. Some Techniques of Operational Research. English Universities Press, London, 1962, $153 \mathrm{p}$.

[11] Lindgren G. OZ-12 Risk Evaluation. OZ Technology Inc., Post Falls IA, 1992, $2 \mathrm{p}$.

[12] MACS Releases Refrigerant Survey Results. Mobile Air Conditioning Society Worldwide, Lansdale PA, 29th October, 2002, 2 p.

[13] Dieckmann J, Bentley J, Varone A. Non-Inert Refrigerant Study for Automotive Applications Final Report. Arthur D. Little, Contract DTRS-57-89-D00007 US Department of Energy, November, 1991, 76 p.

[14] Maclaine-cross IL. Insurance Risk for Hydrocarbon Refrigerants in Car AirConditioners. Refrigeration Science and Technology Proceedings, International Institute of Refrigeration, Proceedings of meeting of Scientific Commissions E2, E1, B1, B2, Melbourne (Australia), February 11-14th, 1996, p. 262-71. 
[15] Sylvester S, Chia S, Bertram J, Gourlay B, Raman R. Use of ER12 Hydrocarbon Refrigerant in Automobile Air-Conditioners. Safety Report for Boral Energy, Granherne Pty Ltd, 1999, 470 p.

[16] Monthly Defect Investigation Report. National Highway Traffic Safety Administration, Washington DC, July, 1994, 10 p.

[17] Waring P. Letter to Michael Roberts. Land Transport Safety Authority, New Zealand, 28th August, 1996, 1 p.

[18] Moroney MJ. Facts from Figures. Penguin Books, UK, 1956, 472 p.

[19] Lunde H, Lorentzen G. Accidents and critical situations due to unintentional escape of refrigerants: a survey of cases in Norway over the last two decades. Int J Refrigeration 1994;17;371-73.

[20] Lindgren L. Risk Assessment of OZ-12 Refrigerant Discharge due to Leaks in an Automobile's Air Conditioning System, OZ Technology Inc., Post Falls IA, 1993, $5 \mathrm{p}$.

[21] Maclaine-cross IL. A Brief Report on Pilot Experiments to Measure the Insurance Risk of Hydrocarbon Refrigerants in Motor Cars. School of Mechanical and Manufacturing Engineering, The University of New South Wales, Sydney, 1994, 8 p.

\section{Nomenclature}

$c$ average mass of replacement refrigerant consumed in charging a MACS $(\mathrm{kg})$

$C$ consumption rate of replacement refrigerant for MACS in country $\left(\mathrm{kg} \mathrm{s}^{-1}\right)$

$f$ frequency density of charge termination $\left(\mathrm{s}^{-1}\right)$

$L$ average charge life (s)

$N$ number of MACS charged with replacement refrigerant in a country

$t$ time (s)

$T$ time of charging (s)

$\delta$ Dirac's delta function

$\Delta t$ length of numerical integration periods (s)

Subscripts

$i, j$ integer indices of numerical integration periods

Abbreviations

AU Commonwealth of Australia

MACS Mobile Air Conditioning System

NHTSA US National Highway Traffic Safety Administration

UK United Kingdom of Great Britain and Northern Ireland

US United States of America 